\title{
CRM BUCK CONVERTER WITH HIGH INPUT POWER FACTOR
}

\author{
Abdul Hakeem Memon \\ Institute of Information and Communication Technologies (IICT), \\ Mehran UET, Jamshoro, Sindh, (Pakistan). \\ E-mail: hakeem.memon@faculty.muet.edu.pk \\ ORCID: https://orcid.org/0000-0001-8545-3823
}

Manzoor Ali

Institute of Information and Communication Technologies (IICT),

Mehran UET, Jamshoro, Sindh, (Pakistan).

E-mail: manzoorabro84@gmail.com

ORCID: https://orcid.org/0000-0002-6430-472X

Zubair Ahmed Memon

Institute of Information and Communication Technologies (IICT),

Mehran UET, Jamshoro, Sindh, (Pakistan).

E-mail: zubair.memon@faculty.muet.edu.pk

ORCID: https://orcid.org/0000-0001-5967-3152

Ashfaque Ahmed Hashmani

Institute of Information and Communication Technologies (IICT),

Mehran UET, Jamshoro, Sindh, (Pakistan).

E-mail: ashfaque.hashmani@faculty.muet.edu.pk ORCID: https://orcid.org/0000-0001-6412-211X

Recepción: 15/12/2020 Aceptación: 10/03/2021 Publicación: 07/05/2021

\section{Citación sugerida:}

Memon, H. A., Ali, M., Memon, Z. A., y Hashmani, A. A. (2021). CRM Buck Converter with High Input Power Factor. 3C Tecnología. Glosas de innovación aplicadas a la pyme, Edición Especial, (mayo 2021), 149-161. https://doi.org/10.17993/3ctecno.2021.specialissue7.149-161 


\section{ABSTRACT}

The buck converter is generally utilized in many applications because of various advantages like maintaining high efficiency for the wide range of input voltage, cost reduction, low output voltage, protection against inrush current and lifetime improvement. However, when on-time of buck converter is kept constant, the input voltage and current remains out of phase that cause's low PF and high total harmonic distortion (THD). Therefore a power factor improvement technique is implemented in this paper that permits the average input current sinusoidal without need of extra converter to work in cascade with buck converter. The critical conduction mode (GRM) buck converter operating with constant on-time (COT) control scheme have low PF because of harmonic contained input current waveform. So in order to make the input current waveform as a sinusoidal by changing the on-time of buck switch, a variable-on-time (VOT) control scheme for CRM buck converter is proposed in this paper. The theoretical analysis is given, and the simulation results confirm the advantages of the proposed control scheme. The object of the research paper is to propose the control scheme to realize high PF for CRM buck converter by only modulating the on-time of buck switch and without need of extra converter to work with buck converter.

\section{KEYWORDS}

Buck Converter, Critical Conduction Mode (CRM), Power Factor (PF), DG/DG Converters, Constant On-Time (COT), Variable On-Time (COT). 


\section{INTRODUCTION}

Power electronic innovation is utilized in different types of present day equipment's which has made our life easier, lavish and simpler. However, this innovation depends on semiconductor devices, because of which the shape of average input current is distorted. The distorted current has different disadvantages, for example, increased power loss, noise and voltage distortion etc. So the industries have formed different standards like IEC61000-3-2 limit and IEEE 519. In order to meet relevant harmonic standard and reducing input current distortion, various researchers have proposed different types of power factor correction (PFG) converters (Memon et al., 2020a, 2020b, 2020c). The DG/DG converters or choppers such as buck, boost and buck-boost etc. are normally employed for PFG application. Each converter has its own advantages and disadvantages. The buck converter now days have attracted the attention of the many researchers (Endo et al., 1992; Memon et al., 2019a, 2019b, 2019c 2019d, 2019e). Its advantages include less voltage stress on the switch, low component cast, low output voltage, low inrush current, protection against short circuit and high efficiency at universal input voltage. However, the input PF of buck converter in low because of dead zone in the average input current that is present until input voltage is more than output voltage. It causes the input current to contain large harmonic disturbances.

For modifying the performance of buck converter, various researchers have proposed various techniques and control schemes (Endo et al., 2020; Memon et al., 2019a, 2019b, 2019c 2019d, 2019e).

In Endo et al. (1992), buck converter is introduced for PF improvement. The application along with analysis and modeling operating in discontinuous current mode (DCM) is discussed in Lee et al. (1997). The work in Spiazzi et al. (2000) has put forward a converter to compensate the dead zone in buck converter. In Huber et al. (2009), the analysis and evaluation of DCM buck converter is given. The bridgeless buck converter is introduced to enhance the efficiency in Jang et al. (2010). The research in Wu et al. (2011) has discussed various aspects regarding the design of buck converter with constant on-time control scheme (COTG). 
In Lamar et al. (2012), the AC/DC driver working in boundary current mode for tapped inductor buck converter is introduced to replace incandescent lamp by high brightness light emitting diode. For the reduction of input current harmonic for high brightness light emitting diode, a control scheme is proposed in Wu et al. (2012). In Ki et al. (2012), a new technique is introduced to reduce losses due to transformer in buck converter. The interleaved critical current mode (CRM) buck converter is introduced in Choi et al. (2012) to increase efficiency.

In Fardoun et al. (2014), a bridgeless buck is proposed to increase the efficiency. For compensating dead zone, double integrated buck converter is introduced for power supplies (Sichirollo et al., 2014). The integration of another converter with buck converter is discussed to enhance the PF in Liu et al. (2020). The works in Memon et al. (2016), Memon et al. (2018a, 2018b) and Memon et al. (2019a, 2019b, 2019c 2019d, 2019e) have introduced various control schemes and topologies for buck converter to attain high PF and efficiency.

In this paper, a PF improvement technique is implemented for CRM buck converter that permits the average input current to be sinusoidal. It can improve input PF without need of other converter to work with buck during dead zone time and also need only one feed forward circuit.

This paper is divided into six sections. In section 2, the operation states of CRM buck converter are analyzed with traditional constant on-time (COT) control scheme. The introduced VOT control scheme is discussed in section 3. Then the comparative analysis is discussed in section 4 in terms of PF. In section 5, the effectiveness of proposed topology is evaluated by simulation results. Finally, some conclusions are drawn in section 6 .

\section{RESEARCH METHODOLOGY}

The research methodology is based on:

1. Mathematical analysis of the operating principle of the traditional control scheme for BCM IBBC with the help of MATHCAD software.

2. Analysis of input PF of BCM integrated BBC. 
3. Introducing the proposed control scheme to obtain high PF with low THD.

4. Comparative analysis of the converter for COT control scheme and VOT control scheme strategy in terms of input PF and THD.

5. Developing the simulation model of the converter with traditional and proposed control scheme with the help of MATLAB software.

6. Confirming the results.

\section{CONVENTIONAL COTCONTROL SCHEME FOR BUCK CONVERTER}

Figure 1 shows the main circuit of the buck converter.

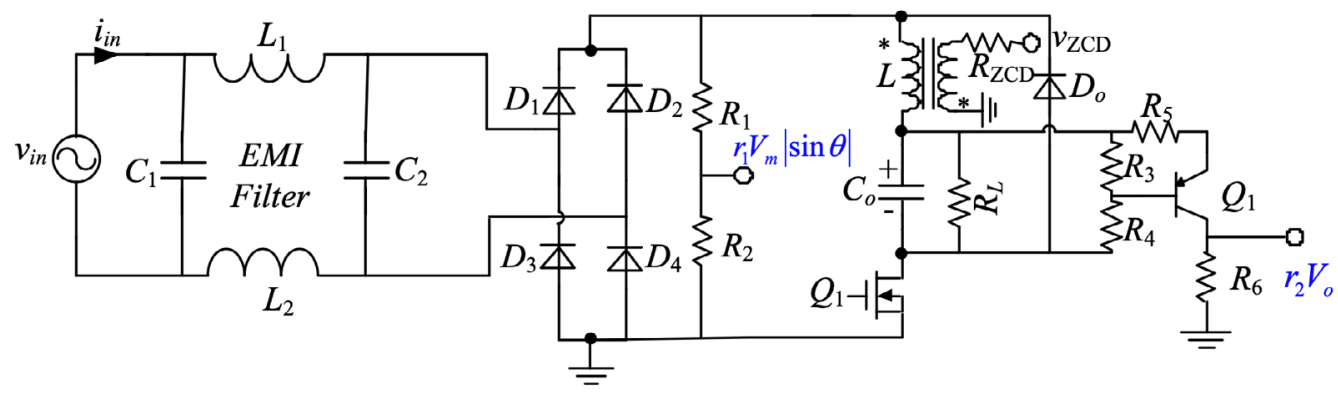

Figure 1. Schematic Diagram of Buck Converter.

Source: (Memon et al., 2019a).

The input voltage and rectified input voltage is expressed as

$$
v_{\text {in }}(\theta)=v_{g}=\sqrt{2} V_{r m s} \sin \theta
$$

Where $V_{r m s}$ is the rms value

When buck switch is on, the inductor voltage is expressed as

$$
L \frac{d i_{L}}{d t}=\sqrt{2} V_{r m s}|\sin \theta|-V_{o}
$$

where $\theta_{0}=\arcsin \frac{V_{\text {boundary }}}{\sqrt{2} V_{r m s}}$

So its peak value is

$$
i_{L_{-} p k}(\theta)=\frac{\sqrt{2} V_{r m s}|\sin \theta|-V_{o}}{L} t_{o n}
$$


Where $t_{\text {on }}$ is the on-time of the switch

While $Q_{\text {buck }}$ is off, the inductor is discharged through load.

$$
-L \frac{d i_{L}}{d t}=V_{o}
$$

For each switching cycle, the value of off-time is calculated from inductor's volt-second balance

$$
t_{\text {off }}=\frac{L}{V_{o}} i_{L(p k 1)}(\theta)
$$

From (3) and (5), the following relation is obtained

In addition

$$
t_{\text {off }}=\frac{\sqrt{2} V_{r m s}|\sin \theta|-V_{o}}{V_{o}} t_{o n}
$$

$$
t_{s}=t_{o n}+t_{o f f}
$$

Substituting (6) into (7)

$$
t_{s}=\left(\frac{\sqrt{2} V_{r m s}|\sin \theta|}{V_{o}}\right) t_{o n}
$$

The value of average input current for buck converter is got as

$$
i_{\text {buck(avg) }}(\theta)=\frac{i_{L_{-} p k}(\theta) t_{o n}}{2 t_{s}}
$$

Substituting (3) and (8) into (9)

$$
i_{\text {buck (avg) }}(\theta)=i_{\text {buck }(\text { COTCS })}(\theta)=\frac{t_{\text {on }} V_{o}}{2 L}\left(\frac{\sqrt{2} V_{r m s}|\sin \theta|-V_{o}}{\sqrt{2} V_{r m s}|\sin \theta|}\right)
$$

Based on (1) and (10), the input power of the buck converter is expressed as

$$
P_{\text {in }(\text { СоTCS })}=\frac{V_{o} t_{o n}}{2 \pi L} \int_{\theta_{0}}^{\pi-\theta_{0}}\left(\sqrt{2} V_{r m s}|\sin \theta|-V_{o}\right) d \theta
$$

Now $t_{\text {on }}$ can be calculated by assuming the efficiency of buck converter as $100 \%$

$$
t_{o n}=\frac{2 \pi P_{o} L}{\int_{\theta_{0}}^{\pi-\theta_{0}} V_{o}\left(\sqrt{2} V_{r m s}|\sin \theta|-V_{o}\right) d \theta}
$$

And input power factor can be calculated as

$$
P F=\frac{P_{i n}}{V_{r m s} I_{r m s}}
$$


Based on (11-13) and specification, the curve of the input PF can be drawn and is given in Figure 2 from which it can be concluded that the input $\mathrm{PF}$ is low for universal input voltage range.

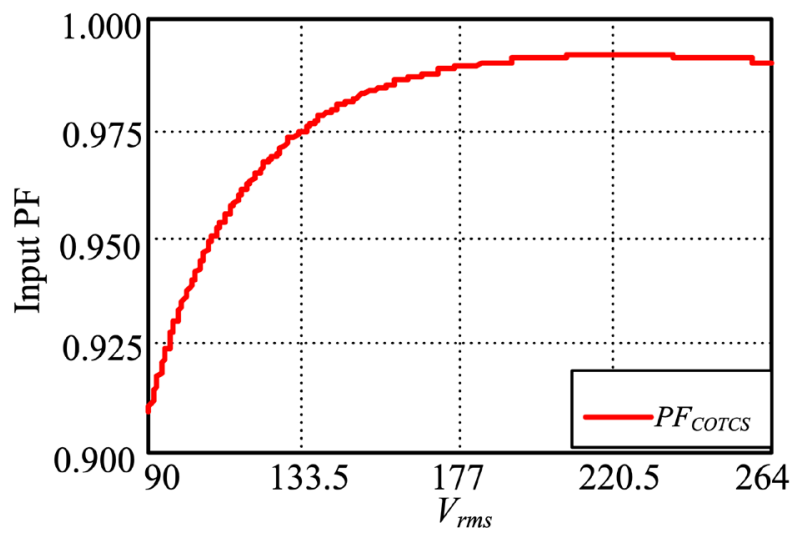

Figure 2. Input PF of COTCS [Mathcad eq:(10-14)].

\section{PROPOSED VOT CONTROL SCHEME FOR CRM BUCK CONVERTER}

For obtaining high PF for the buck converter, the on-time of $Q_{\text {buck }}$ in $(10)$ should vary as

$$
t_{o n(V O T C)}=k_{o n 1} \frac{\left(\sqrt{2} V_{r m s}|\sin \theta|\right)^{2}}{V_{o}\left(\sqrt{2} V_{r m s}|\sin \theta|-V_{o}\right)}
$$

Where $k_{\text {onl }}$ is a constant

Substituting (14) into (10), the average input current of the buck converter is

$$
i_{\text {buck(YOTC) }}(\theta)=\frac{\sqrt{2} V_{\text {rms }}|\sin \theta|}{2 L} k_{\text {on1 }}\left(\theta_{0} \leq \theta \leq \pi-\theta_{0}\right)
$$

From (15), it can be seen that if the on-time of the buck converter varies as (14), the input current waveform looks like pure sinusoidal and the $\mathrm{PF}$ is high

Because of the power balance of the input and output, the input current for the unity PF can be expressed as

$$
i_{i n}(\theta)=\frac{\sqrt{2} P_{o}|\sin \theta|}{V_{r m s}}
$$

Based on (15-16), the input current at $\theta_{0}$ can be written as 


$$
i_{i n}\left(\theta_{0}\right)=\frac{k_{\text {on1 }} \sqrt{2} V_{r m s}\left|\sin \theta_{0}\right|}{2 L}=\frac{\sqrt{2} P_{o}\left|\sin \theta_{0}\right|}{V_{r m s}}
$$

From (17), it can be concluded that

$$
k_{o n 1}=\frac{2 P_{o} L}{V_{r m s}^{2}}
$$

\section{COMPARATIVE ANALYSIS}

From (14), the input PF curve with proposed control scheme is shown in Figure 3 which also includes the PF values with traditional control scheme of Figure 2. It can be concluded that the PF of the converter with proposed control is higher as compared to COTC. It can conclude that improvement in $\mathrm{PF}$ is at all input voltage.

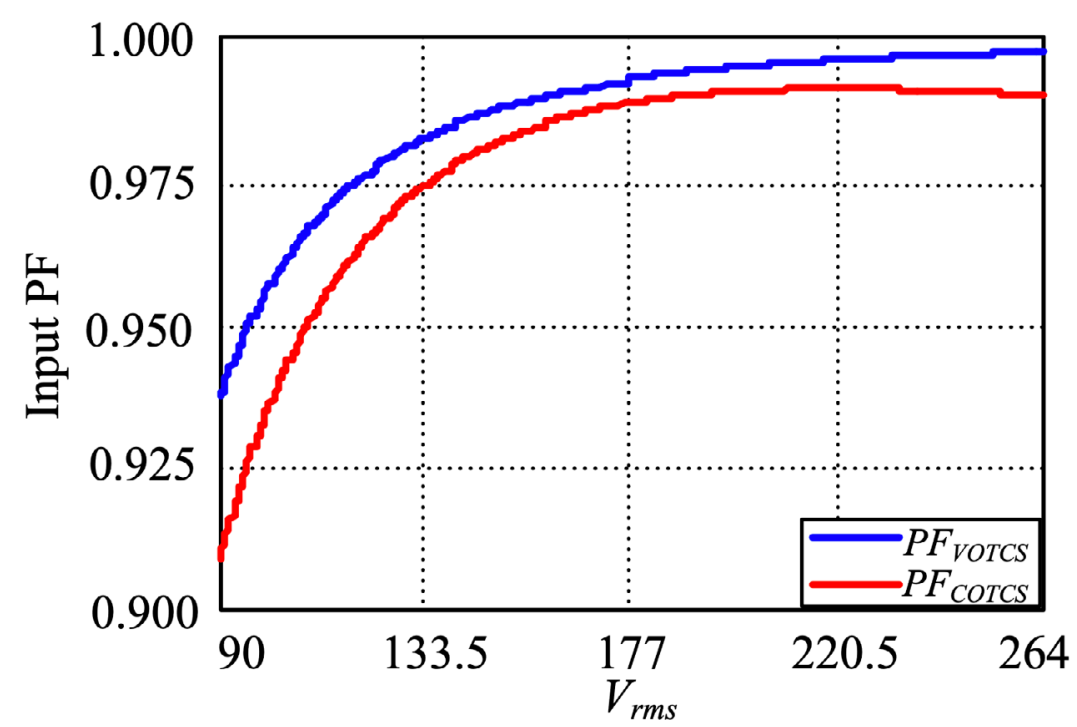

Figure 3. Input PF comparison between COT \& VOT control scheme [Mathcad eq:(10-18)].

The THD comparison of the buck converter with COTCS and VOTCS is depicted in Figure 4. It indicates that THD is reduced in case of VOTCS as compared to COTCS. 


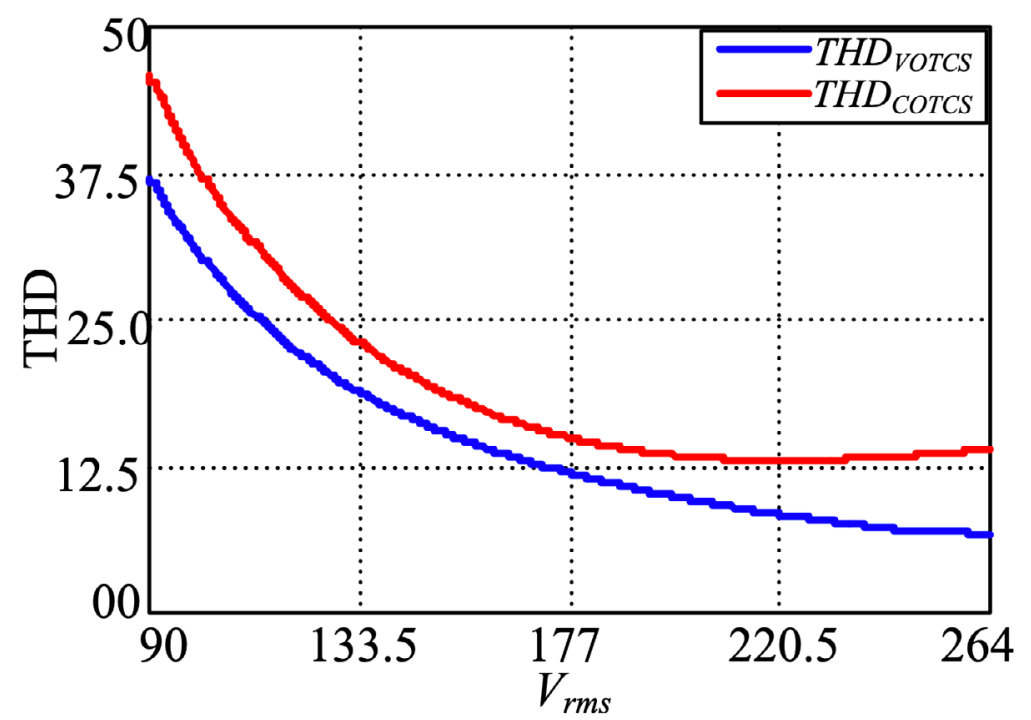

Figure 4. THD comparison between COT \& VOT control scheme [Mathcad eq:(10-18) Relationship between PF and THD].

\section{SIMULATION RESULTS}

In order to verify the effectiveness of VOTCS, simulations results are given. The range of input voltage is $90-264 V_{r m s}$. The output voltage is selected as $80 \mathrm{~V}$. The control IC 6561 will ensure the current to be in CRM. Ideal components are used in simulation

Figure 5 and Figure 6 show the simulation waveforms of $v_{i n}$, \& $i_{i n}$ of buck converter with COTCS and VOTCS at 220VAC inputs, respectively. It can be conducted that current is more sinusoidal in case of VOTCS as compared to COTCS. Thus VOTCS can attain high PF.
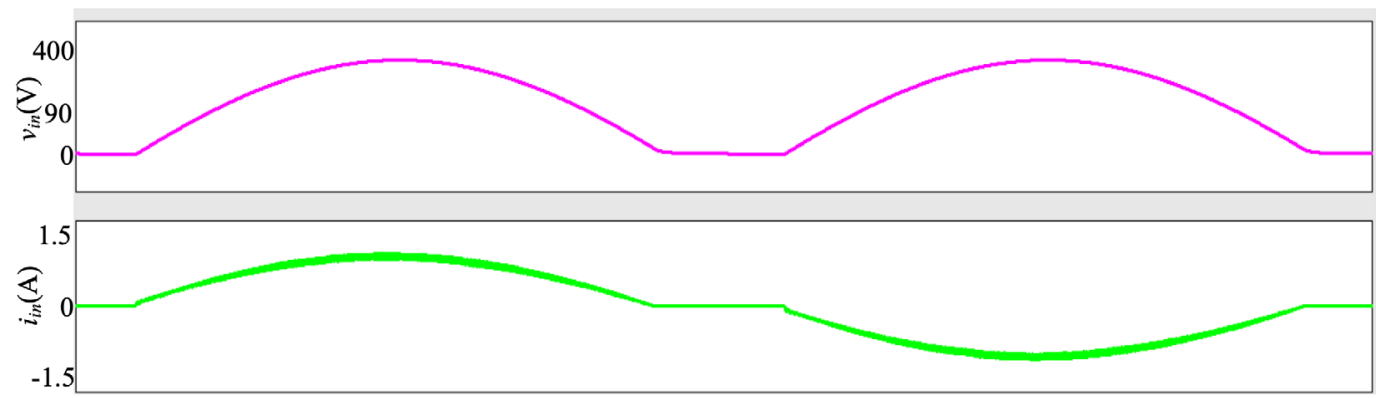

Figure 5. Input voltages and current of buck converter with COT control scheme [Saber Software]. 

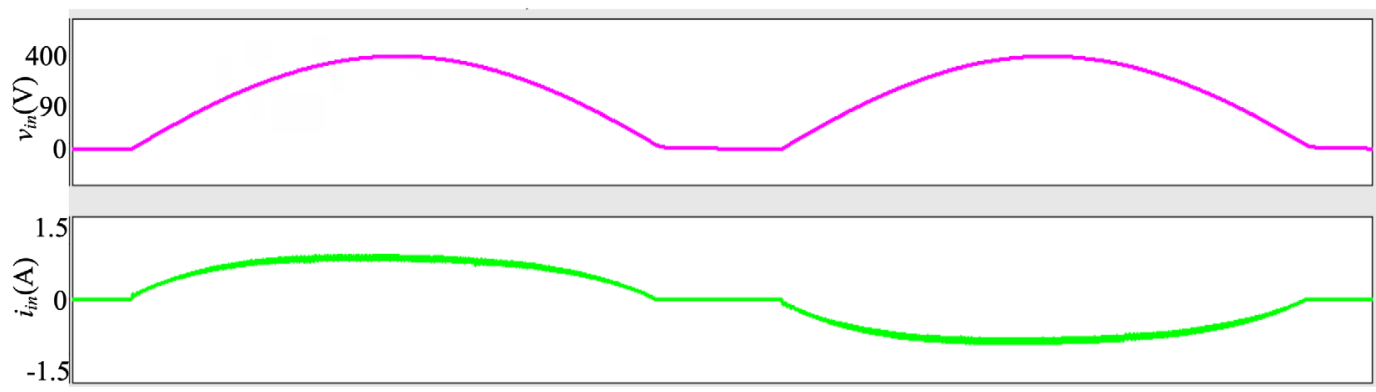

Figure 6. Input voltages and current of buck converter with VOT control scheme [Saber Software].

\section{CONCLUSIONS}

The buck converter is generally utilized in many applications because of various advantages. However, when on-time of buck converter is kept constant, the input voltage and current remains out of phase that cause's low PF and high total harmonic distortion (THD). Therefore, in this paper, a power factor improvement technique is implemented that permits the average input current sinusoidal without need of extra converter to work in cascade with buck converter. With COTCS, the input PF of the buck converter is low. In order to attain high input PF, VOT control scheme is proposed. Simulation results are presented for the verification of the analysis.

\section{REFERENCES}

Choi, H. (2012). Interleaved boundary conduction mode (BCM) buck power factor correction (PFG) converter. IEEE Transactions on Power Electronics, 28(6), 2629-2634. https://doi.org/10.1109/TPEL.2012.2222930

Endo, H., Yamashita, T., \& Sugiura, T. (1992). A high-power-factor buck converter. In PESC'92 Record. 23rd Annual IEEE Power Electronics Specialists Conference (pp. 10711076). IEEE. https://doi.org/10.1109/PESG.1992.254766

Fardoun, A. A., Ismail, E. H., Khraim, N. M., Sabzali, A. J., \& Al-Saffar, M. A. (2014). Bridgeless high-power-factor buck-converter operating in discontinuous capacitor voltage mode. IEEE Transactions on Industry Applications, 50(5), 3457-3467. https://doi.org/10.1109/TIA.2014.2305771 
Huber, L., Gang, L., \& Jovanovic, M. M. (2009). Design-oriented analysis and performance evaluation of buck PFC front end. IEEE Transactions on power electronics, 25(1), 85-94. https://doi.org/10.1109/TPEL.2009.2024667

Jang, Y., \& Jovanović, M. M. (2010). Bridgeless high-power-factor buck converter. IEEE Transactions on Power Electronics, 26(2), 602-611. https://doi.org/10.1109/ TPEL.2010.2068060

Ki, S. K., \& Lu, D. D. G. (2012). A high step-down transformerless single-stage singleswitch AC/DG converter. IEEE Transactions on Power Electronics, 28(1), 36-45. https:// doi.org/10.1109/TPEL.2012.2195505

Lamar, D. G., Fernandez, M., Arias, M., Hernando, M. M., \& Sebastian, J. (2012). Tapped-inductor buck HB-LED AC-DC driver operating in boundary conduction mode for replacing incandescent bulb lamps. IEEE Transactions on Power Electronics, 27(10), 4329-4337. http://dx.doi.org/10.1109/TPEL.2012.2190756

Lee, Y. S., Wang, S. J., \& Hui, S. Y. R. (1997). Modeling, analysis, and application of buck converters in discontinuous-input-voltage mode operation. IEEE Transactions on Power Electronics, 12(2), 350-360. https://doi.org/10.1109/63.558762

Liu, X., Wan, Y., He, M., Zhou, Q., \& Meng, X. (2020). Buck-Type Single-Switch Integrated PFC Converter With Low Total Harmonic Distortion. IEEE Transactions on Industrial Electronics. https:/ /doi.org/10.1109/TIE.2020.3007121

Memon, A. H., \& Yao, K. (2018a). UPG strategy and implementation for buck-buck/ boost PF correction converter. IET Power Electronics, 11(5), 884-894. https://doi. org/10.1049/iet-pel.2016.0919

Memon, A. H., Baloach, M. H., Sahito, A. A., Soomro, A. M., \& Memon, Z. A. (2018b). Achieving High Input PF for CRM Buck-Buck/Boost PFG Converter. IEEE Access, 6, 79082-79093. https://doi.org/10.1109/ACGESS.2018.2879804

Memon, A. H., Memon, M. A., Memon, Z. A., \& Hashmani, A. A. (2019a). Critical Conduction Mode Buck-Buck/Boost Converter with High Efficiency. 3C Tecnología. 
Glosas de innovación aplicadas a la pyme. Edición Especial, Noviembre 2019, 201-219. http:// dx.doi.org/10.17993/3ctecno.2019.specialissue3.201-219

Memon, A. H., Memon, Z. A., Shaikh, N. N., Sahito, A. A., \& Hashmani, A. A. (2019b). Boundary conduction mode modified buck converter with low input current total harmonic distortion. Indian Fournal of Science and Technology, 12, 17. http://doi. org/10.17485/ijst/2019/v12i17/144613

Memon, A. H., Nizamani, M. O., Memon, A. A., Memon, Z. A., \& Soomro, A. M. (2019c). Achieving High Input Power Factor for DCM Buck PFC Converter by Variable Duty-Cycle Control. 3C Tecnología. Glosas de innovación aplicadas a la pyme. Edición Especial, Noviembre 2019, 185-199. http:/ /dx.doi.org/10.17993/3ctecno.2019. specialissue3.185-199

Memon, A. H., Noonari, F. M., Memon, Z., Farooque, A., \& Uqaili, M. A. (2020a). $\mathrm{AC} / \mathrm{DC}$ critical conduction mode buck-boost converter with unity power factor. $3 C$ Tecnología. Glosas de innovación aplicadas a la pyme. Edición Especial, Abril 2020, 93-105. http://doi.org/10.17993/3ctecno.2020.specialissue5.93-105

Memon, A. H., Pathan, A. A., Kumar, M., \& Sahito, A. A., \& Memon, Z. A. (2019d). Integrated buck-flyback converter with simple structure and unity power factor. Indian Fournal of Science and Technology, 12(17), 1-8. http://doi.org/10.17485/ ijst/2019/v12i17/144612

Memon, A. H., Shaikh, N. N., Kumar, M., \& Memon, Z. A. (2019e). Buck-buck/boost converter with high input power factor and non-floating output voltage. International Journal of Computer Science and Network Security, 19(4), 299-304.

Memon, A. H., Yao, K., Ghen, Q., Guo, J., \& Hu, W. (2016). Variable-on-time control to achieve high input power factor for a CRM-integrated buck-flyback PFC converter. IEEE Transactions on Power Electronics, 32(7), 5312-5322. https: / / www.semanticscholar. org/paper/Variable-On-Time-Controlled-Flyback-PFC-Converter-Yan-Xu/6fe0a 89e8c674dc3a4c58402b7fc27e8d5ad8b77 
Memon, A., Samejo, J. A., Memon, Z. A., \& Hashmani, A. A. (2020b). Realization Of Unity Power Factor For Ac/Dc Boundary Conduction Mode Flyback Converter With Any Specific Turn's Ratio. Journal of Mechanics Of Continua And Mathematical Sciences, (spl6). https://doi.org/10.26782/jmcms.spl.6/2020.01.00014

Memon, A., Shaikh, S. A., Memon, Z. A., Memon, A. A., \& Memon, A. A. (2020c). DCM Boost Converter with High Efficiency. Journal Of Mechanics Of Continua And Mathematical Sciences, (spl6). https://doi.org/10.26782/jmcms.spl.6/2020.01.00006

Sichirollo, F., Alonso, J. M., \& Spiazzi, G. (2014). A novel double integrated buck offline power supply for solid-state lighting applications. IEEE transactions on industry applications, 51(2), 1268-1276. https://doi.org/10.1109/TIA.2014.2350071

Spiazzi, G., \& Buso, S. (2000). Power factor preregulators based on combined buckflyback topologies. IEEE transactions on Power Electronics, 15(2), 197-204. https://doi. org/10.1109/63.838091

Wu, X., Yang, J., Zhang, J., \& Qian, Z. (2012). Variable on-time (VOT)-controlled critical conduction mode buck PFC converter for high-input AC/DG HB-LED lighting applications. IEEE Transactions on power Electronics, 27(1 1), 4530-4539. https:// ieeexplore.ieee.org/document/6030954

Wu, X., Yang, J., Zhang, J., \& Xu, M. (2011). Design considerations of soft-switched buck PFC converter with constant on-time (COT) control. IEEE transactions on power electronics, 26(11), 3144-3152. https://ieeexplore.ieee.org/document/5753946 